Supplement of Earth Surf. Dynam., 9, 445-462, 2021

https://doi.org/10.5194/esurf-9-445-2021-supplement

(C) Author(s) 2021. CC BY 4.0 License.

(c) (1)

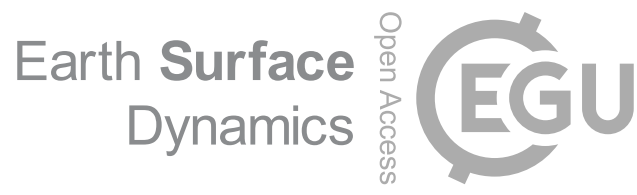

Supplement of

\title{
Interactions between deforestation, landscape rejuvenation, and shallow landslides in the North Tanganyika-Kivu rift region, Africa
}

Arthur Depicker et al.

Correspondence to: Arthur Depicker (arthur.depicker@kuleuven.be)

The copyright of individual parts of the supplement might differ from the article licence. 


\section{S1 Deforestation wave in rejuvenated and relict landscapes}

\section{a) Rejuvenated}

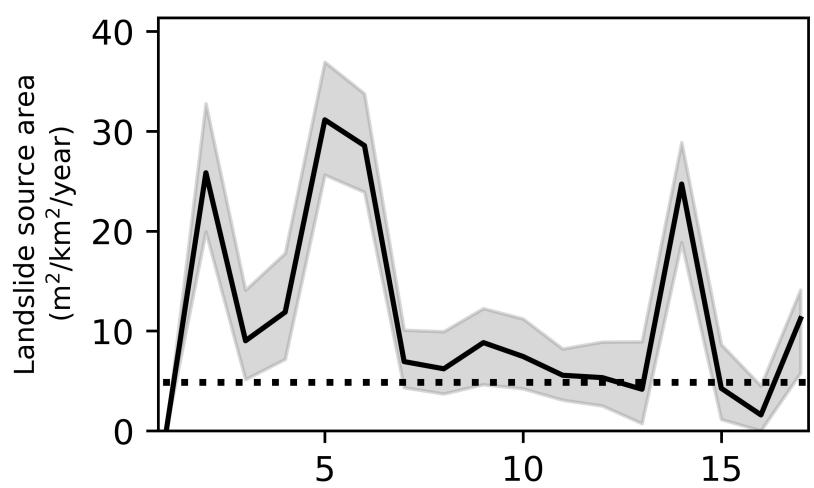

\section{b) Relict}

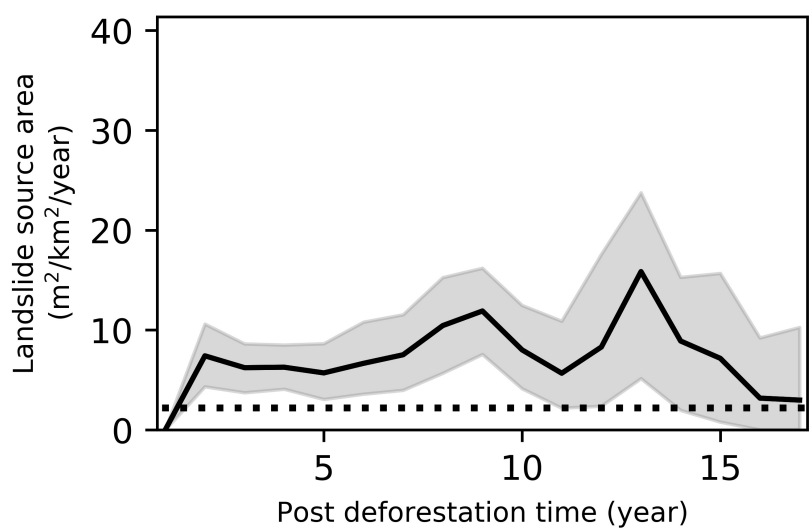

Figure S1. Deforestation-induced landslide wave in different geomorphic contexts. Overall landslide source area $\left(L S_{S}, \mathrm{~m}^{2} \mathrm{~km}^{-2}\right.$ year $^{-1}$ ) in function of time elapsed since deforestation. The grey area represents the $90 \%$ confidence interval, derived from 100 iterations of $L S_{S}$ calculations (Section 3.2.4). The dotted line shows the overall erosion rates in the different contexts. a) Landslide response to deforestation in rejuvenated landscapes, characterized with 193 landslide instances. The irregular curve suggests that, in order to better characterize the deforestation-induced landslide wave, we need more landslide and deforestation observations and over a larger area. b) Landslide response to deforestation in relict landscapes, characterized with 181 landslide instances. The dotted line represents the background erosion rate in relict landscapes. 